\title{
NUMERICAL SIMULATION OF RESIDUAL STRESSES AND DISTORTIONS IN BUTT WELD IN SIMULATION PROGRAMME SYSWELD
}

The article describes the theoretical knowledge of the residual stresses induced during welding in butt welded joint and the possibilities of their simulations in a simulation programme SYSWELD. In conclusion are compared experimental and simulated results.

Keywords: Butt weld, steel S355J2G3, SYSWELD.

\section{Introduction}

Welding induced residual stress and distortions are among the most situated subjects for welded structures. The localized heating and non-uniform cooling during welding results in a complex distribution of the residual stress in the joint region, as well as the often undesirable deformation or distortion of the welded structure. As residual stress and distortion can significantly impair the performance and reliability of the welded structure, they must be properly dealt with during design, fabrication and in-service use of the welded structures [1].

\section{Theoretical part}

\subsection{Residual stress and distortions}

In a welded joint, the expansion and contraction forces act on the weld metal and its adjacent base metal. As the weld metal solidifies and fuses with base metal, it is in its maximum expanded state. However, at this point, the weld metal and its adjacent base metal absorbed the high temperatures and have little strength or rigidity. The volume expansion caused local thickening in the weld area but is incapable of causing a significant amount of plastic strains in the cooler joint neighborhoods. On cooling, it attempts to contract to the volume that it would normally occupy at the lower temperature, but it is restrained from doing so by the adjacent cooler base material. Stresses develop within the weld, finally reaching the yield strength of weld metal. At this point the weld stretches, or yields and thins out, thus adjusting to the volume requirements of the lower temperature, but only those stresses that do not exceed the yield strength of the weld metal, or the elastic mechanical strain, are relieved by this accommodation [1].
Residual stresses are a consequence ofinteractions among time, temperature,deformationand microstructure (Fig. 1). Material or material-related characteristics that in fluence the development of residual stress include thermal conductivity, heat capacity, thermal expansivity, elastic modulus and Poisson's ratio, plasticity, thermodynamics and kinetics of transformations, mechanisms of transformations, and transformation plasticity [2].

The fundamental material properties are, of course, temperature dependent. Fig. 1 illustrates how several key properties might vary with temperature [2].

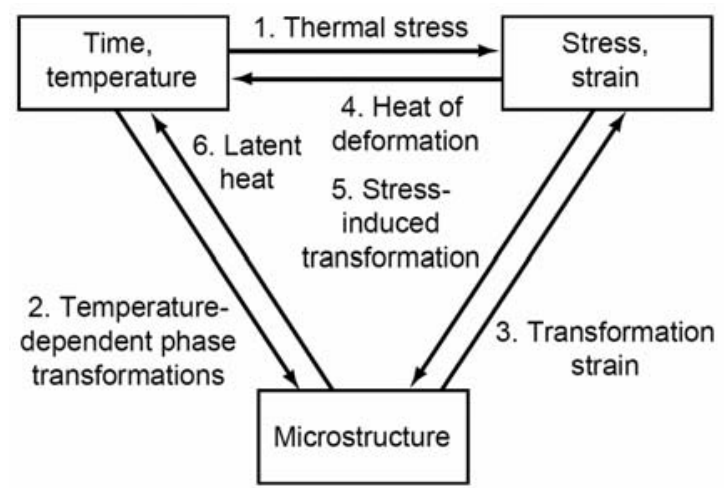

Fig. 1 The coupling of temperature, stress and microstructure [2]

Fig. 2 divides the development of residual stresses in welded seams in three different mechanisms [3].

\footnotetext{
* Radoslav Konar, Milos Mician

Department of Technological Engineering,Faculty of Mechanical Engineering, University of Zilina, Slovakia,E-mail: radoslav.konar@fstroj.uniza.sk
} 
Shrinking stresses: these are stresses formed through uniform cooling of the seam. Caused by expansion restriction of the colder areas at the edge of the weld and base material, tensile stresses develop along and crosswise to the seam.

Quenching stresses: If cooling is not homogenous, the surface of the weld cools downfaster than the core areas. If the high-temperature limit of elasticity is exceeded due to buildupstress differences, pressure stresses will be present at the weld surface after cooling. Incontrast, the core shows tensile stresses in cold condition.

Transition stresses: Transitions in the ferrite and perlite stage cause normally only residualstresses, because within this temperature range the yield strength of the steel is so low thatgenerated stresses can be undone by plastic deformations [3]

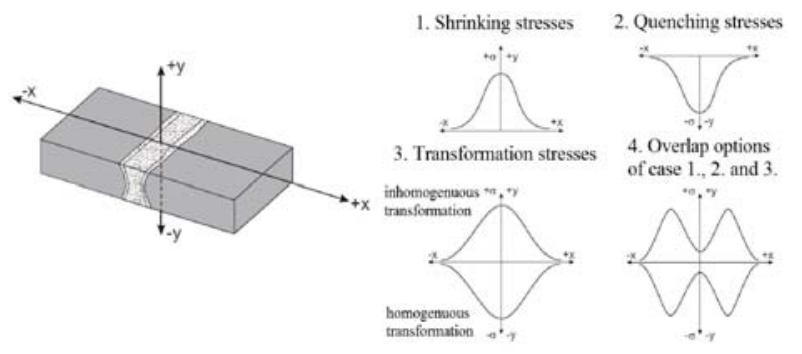

Fig. 2 Development of residual stresses [3]

The plastic strain results in permanent deformation of the welded structure after the welding. This is called welding-induced distortion. The mode of welding-induced distortion could show up in-plane deformation such as stretching and out-of-plane deformation such as bending, rotation or buckling. Typical welding-induced distortion is shown in Fig. 3 [2].

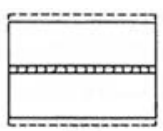

(a)

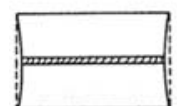

(d)

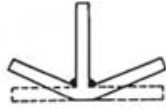

(b)

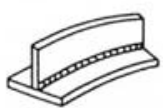

(e)

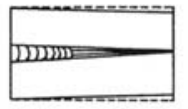

(c)

(f)

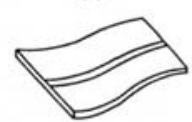

Fig. 3 Various types of welding-induced distortion (a) transverse shrinkage, (b) angular change, (c) rotational distortion,

(d) longitudinal shrinkage, (e) longitudinal bending distortion, (f) buckling distortion [2]

\subsection{SYSWELD}

SYSWELD is a Finite Element software that simulates all usual welding processes such as MMA, MIG, TIG, spot welding, laser welding, heat treatment like bulk hardening, surface hardening, tempering and hardening and tempering, as well as thermo-chemical treatment like case hardening, carbonitriding, nitriding [1].

Simulation of a welding process requires two successive analyses:

- first a thermo-metallurgical analysis,

- followed by a mechanical analysis.

\subsubsection{Definition of heat source in SYSWELD}

Simulation system SYSWELD used for numerical calculations of heat following heat sources: 2D Gaussian model - for surface thermal treatment of material, 3D Gaussian model - for simulation of welding with high power density in impact area and 3D Glodak model - for shielded metal arc welding, submerged arc welding, GTAW, GMAW. Just because of great using variability will be this type of heat source closely described [4].

\section{Experimental part}

This experiment includes analysis of boundary conditions for the simulation of welding in butt weld and simulation thermal analysis, welding-induced distortion and residual stress in simulation programme SYSWELD.

\subsection{Experimental sample}

Model used for the experiment was compounded of two plates of materials S355J2G3. Chemical composition and mechanical properties of steel are in Tab. 1.

Both of the plates have same geometrical properties $(250 \times$ $50 \times 7 \mathrm{~mm}$ ). The fusion faces were prepared according to scheme in Fig. 4. Two parts of experimental sample were tack-welding together without root gap. Run-on and run-off plates were used in welding process. Experimental sample was prepared for welding. Welding joint was welded using the mechanized GMAW process. Constant welding speed was secured by a welding truck.

\subsection{Experimental measurements before, during and after welding}

Before welding were measured distortion in y-axis of sample in 9 points (Fig. 4), during welding were measured welding parameters and thermal cycles in three points. After welding and cooling to ambient temperature $\left(20^{\circ} \mathrm{C}\right)$ were measured distortions again. Distortions in y-axis were measured from reference point. Displacements were measured with a mechanical standing micrometer. 


\begin{tabular}{|c|c|c|c|c|c|c|c|c|}
\hline \multicolumn{1}{|c|}{ Chemical composition } \\
\hline max. \% & $\mathrm{C}$ & $\mathrm{Si}$ & $\mathrm{Mn}$ & $\mathrm{P}$ & $\mathrm{S}$ & $\mathrm{V}$ & $\mathrm{Nb}$ & $\mathrm{Ti}$ \\
\hline S355J2G3 & 0.20 & 0.55 & 1.60 & 0.035 & 0.035 & - & - & - \\
\hline \multicolumn{8}{|c|}{ Mechanical properties } \\
\hline \multirow{2}{*}{ S355J2G3 } & $\mathrm{R}_{\mathrm{m}}[\mathrm{MPa}]$ & $\mathrm{R}_{\mathrm{e}}[\mathrm{MPa}]$ & $\mathrm{A}_{5}[\%]$ & $\mathrm{KV}[\mathrm{J}]$ \\
\cline { 2 - 7 } & \multicolumn{1}{|c|}{$\min .490$} & \multicolumn{2}{c|}{$\min .355$} & min. 20 & min. 27 \\
\hline
\end{tabular}
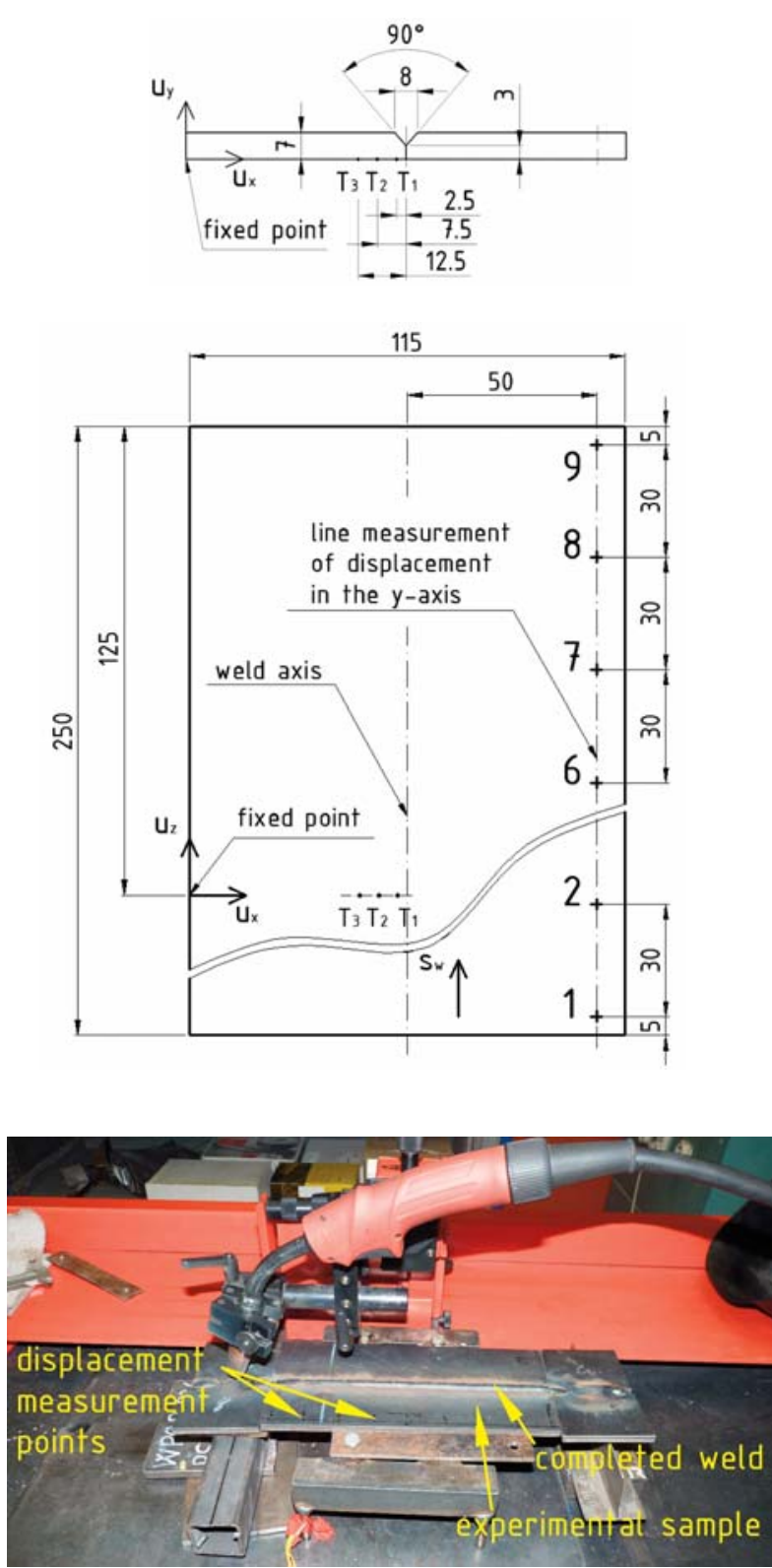

Fig. 4 Experimental sample, scheme (up), real sample (down)
Model was fixed on plane table in fixed point during displacement measurement with mechanical clamp. After all measurements the weld was analyzed. Complete analysis of weld for simulation in simulation programme SYSWELD contains:

- parameters of welding $U_{w}, I_{w}$ (Tab. 2)

- cross-sectional geometry of the welds (weld metal, heat affected zone),

- welding speed $\left(s_{w}\right)$,

- thermal cycles,

- distortions in y-axis (Tab. 3).

Parameters of welding

Table 2

\begin{tabular}{|ll|c|}
\hline \multicolumn{3}{|c|}{ Parameters of welding } \\
\hline Welding current & $\mathrm{I}_{\mathrm{w}}[\mathrm{A}]$ & 177 \\
\hline Welding voltage & $\mathrm{U}_{\mathrm{w}}[\mathrm{V}]$ & 20 \\
\hline Welding speed & $\mathrm{s}_{\mathrm{w}}\left[\mathrm{mm} \cdot \mathrm{s}^{-1}\right]$ & 4.9 \\
\hline Wire feed rate & $\mathrm{r}_{\mathrm{wf}}\left[\mathrm{m} \cdot \mathrm{min}^{-1}\right]$ & 8 \\
\hline Gas flow rate & $\mathrm{r}_{\mathrm{gf}}\left[1 . \mathrm{min}^{-1}\right]$ & 12 \\
\hline Welding wire diameter & $\mathrm{d}_{\mathrm{ww}}[\mathrm{mm}]$ & 1.2 \\
\hline Real heat input $(\eta=0,85)$ & $\mathrm{Qr}\left[\mathrm{J} \cdot \mathrm{cm}^{-1}\right]$ & 6141 \\
\hline
\end{tabular}
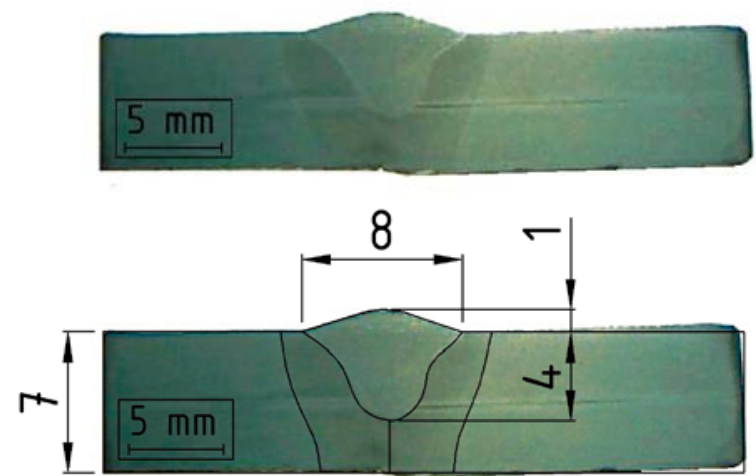

Fig. 5 Macrostructural analysis (up) and digitized macrostructure (down)

Digitizing of weld macrostructures, we get cross-sectional parameters of welds (Fig. 5), which are necessary for the definition of Goldak heat source model and FEM model creating. 


\section{caMMNICOIIONS}

Measured displacements of points in y-axis

Table 3

\begin{tabular}{|c|c|c|c|c|c|c|c|c|c|}
\hline \multicolumn{8}{|c|}{ Measured displacements of points in y-axis [mm] } \\
\hline Point & 1 & 2 & 3 & 4 & 5 & 6 & 7 & 8 & 9 \\
\hline Displacement & 0.54 & 0.51 & 0.49 & 0.47 & 0.46 & 0.47 & 0.49 & 0.51 & 0.54 \\
\hline
\end{tabular}

Temperature cycles were measured by three thermocouples $T_{1}, T_{2}, T_{3}$. Their location is shown inFig. 4 and its graphic view in Fig. 6. Characteristic attributes of temperature cycles are in Tab 4

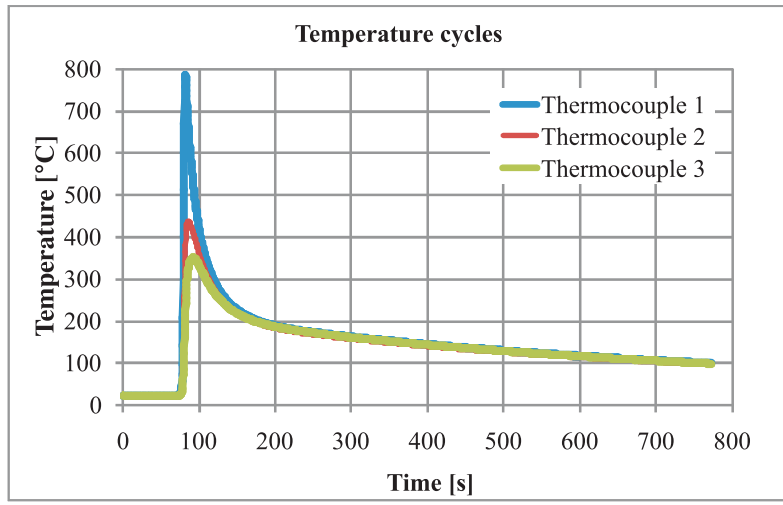

Fig. 6 Measured temperature cycles in three thermocouples

Characteristic attributes of measured temperature cycles Table 4

\begin{tabular}{|c|c|c|c|}
\hline \multicolumn{4}{|c|}{ Characteristic attributes of temperature cycles } \\
\hline Thermocouple & $\mathrm{T}_{\max }\left[{ }^{\circ} \mathrm{C}\right]$ & $\mathrm{r} 300\left[{ }^{\circ} \mathrm{C} \cdot \mathrm{s}^{-1}\right]$ & $\mathrm{t} 100[\mathrm{~s}]$ \\
\hline $1^{\text {st }}$ & 785 & 3.91 & 683 \\
\hline $2^{\text {nd }}$ & 437 & 3.81 & 643 \\
\hline $3^{\text {rd }}$ & 350 & 3.42 & 662 \\
\hline
\end{tabular}

Experimental results will serve as a boundary condition for the simulation in simulation programme SYSWELD.

\subsection{Numerical simulation of welding in simulation programme SYSWELD}

Numerical simulation process consists of several following steps:

1. Creating geometrical model and its distribution to FEM mesh,

2. Definition of input data and boundary condition,

3. Simulation and presentation of results.

The model has the same geometrical dimensions as the exper imental sample.Meshed FEM model can be seen in Fig. 7. Distribution model has 57706 finite elements and 49843 nodes. The smallest element used in the FEM model is in the area of the weld with the dimension of $1.0 \mathrm{~mm} \times 1.0 \mathrm{~mm} \times 1.25 \mathrm{~mm}$.

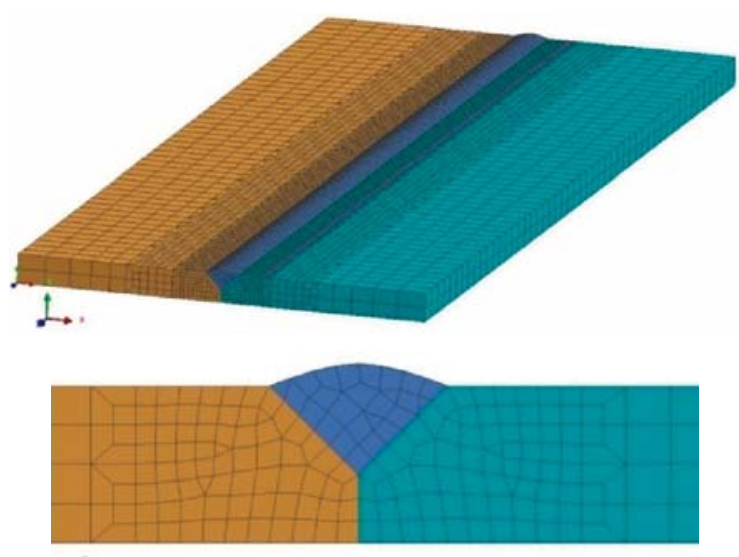

$\therefore$

Fig. 7 FEM model of experimental sample

Input data and boundary conditions used for simulation of thermal analysis are: material database of the model was steel S355J2G3. Parameters of Goldakare in Tab.5.

Parameters of Goldak model Table 5

\begin{tabular}{|cc|c|}
\hline \multicolumn{3}{|c|}{ Parameters of Goldak model } \\
\hline $\mathrm{c}_{1}$ & {$[\mathrm{~mm}]$} & 2 \\
\hline $\mathrm{c}_{2}$ & {$[\mathrm{~mm}]$} & 4 \\
\hline $\mathrm{a}$ & {$[\mathrm{mm}]$} & 4 \\
\hline $\mathrm{b}$ & {$[\mathrm{mm}]$} & 4.25 \\
\hline $\mathrm{Q}$ & {$[\mathrm{W}]$} & 3050 \\
\hline
\end{tabular}

In the thermal analysis, temperature fields, temperature cycleswere simulated. Graphic results of the simulation are in Figs. 8 and 9.

Characteristic attributes of simulated temperature cycles are in Tab. 6.

Characteristic attributes of simulated temperature cycle Table 6

\begin{tabular}{|c|c|c|c|}
\hline \multicolumn{4}{|c|}{ Characteristic attributes of temperature cycles } \\
\hline Thermocouple & $\mathrm{T}_{\max }\left[{ }^{\circ} \mathrm{C}\right]$ & $\mathrm{r} 300\left[{ }^{\circ} \mathrm{C} \cdot \mathrm{s}^{-1}\right]$ & $\mathrm{t} 100[\mathrm{~s}]$ \\
\hline $1^{\text {st }}$ & 866 & 3.75 & 690 \\
\hline $2^{\text {nd }}$ & 500 & 3.75 & 685 \\
\hline $3^{\text {rd }}$ & 398 & 3.75 & 670 \\
\hline
\end{tabular}



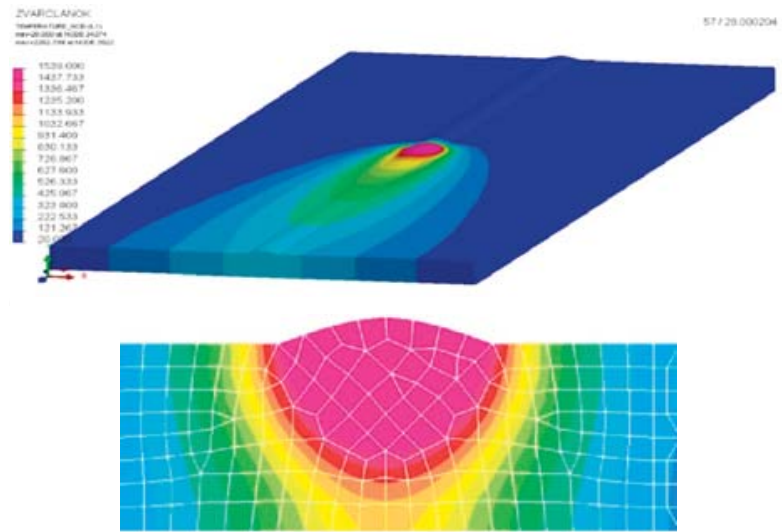

Fig. 8 Simulated temperature fields

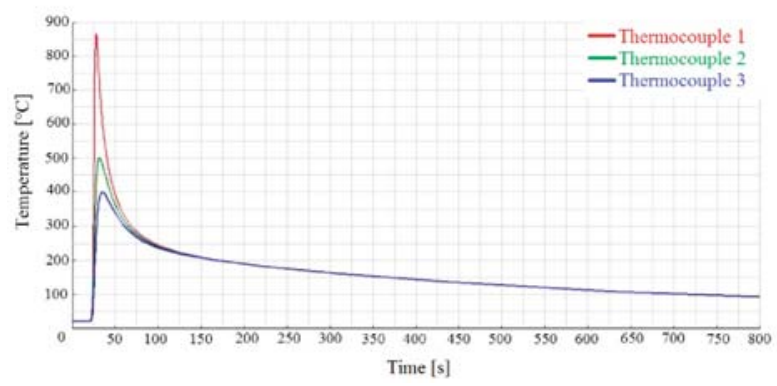

Fig. 9 Simulated temperature cycles in three thermocouples

Free boundary conditions of FEM model were used to calculate mechanical analysis. Free location of model can be seen in Fig. 10. Residual stresses and distortion were simulated in the mechanical simulation. Graphic results of the mechanical simulation are in Figs. 11, 12 and Tab. 7.
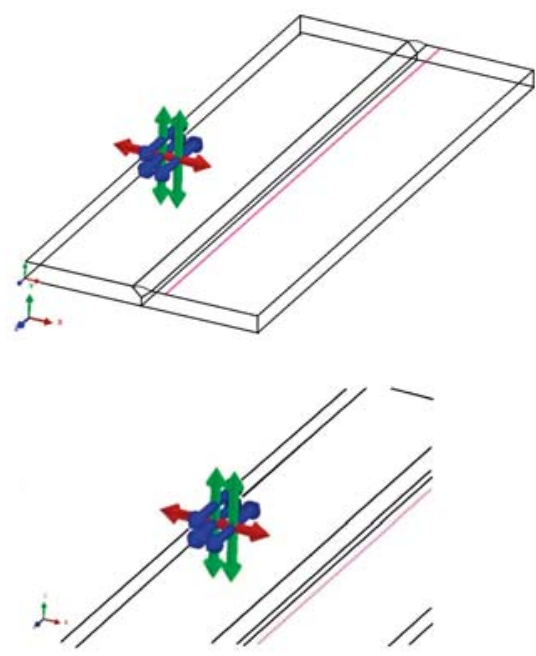

Fig. 10 Clamping condition for mechanical analysis

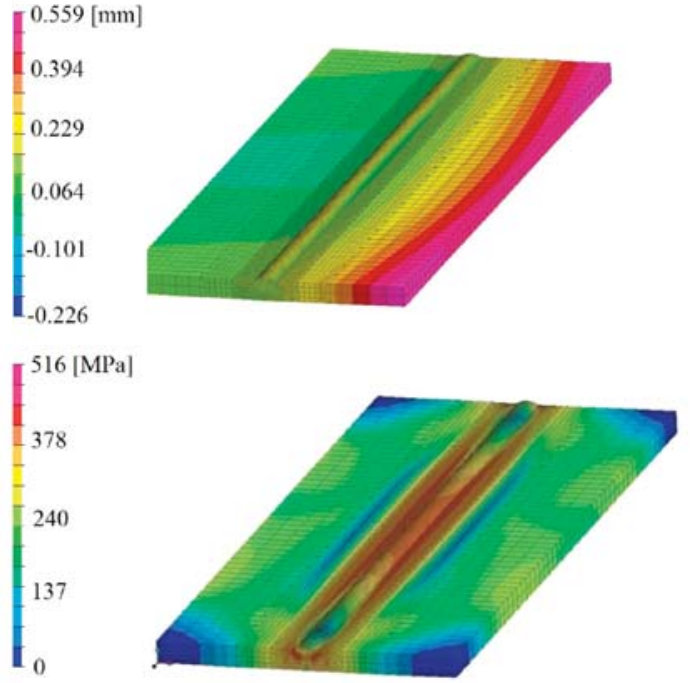

Fig. 11 Simulated displacements in y-axis (up) and residual stresses by Von Misses (down)
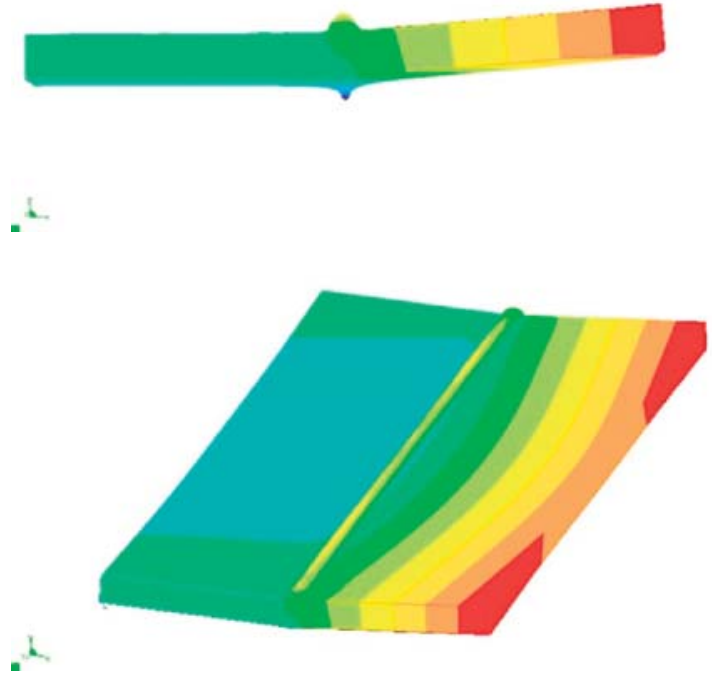

Fig. 12 Deformed shape of FEM model (deformed scale 10)

\section{Conclusion}

Theoretical part of the paper includes information about residual stresses induced during welding and welding simulation in programme SYSWELD. Experimental part includes analysis of boundary conditions and simulation of welding in butt weld. Experimental and simulation results are almost identical. The maximal difference between experimental and simulated characteristic para- 


\section{coMMNICaIIONS}

Simulated displacements of points in y-axis

Table 7

\begin{tabular}{|c|c|c|c|c|c|c|c|c|c|}
\hline \multicolumn{8}{|c|}{ Simulated displacements of points in y-axis [mm] } \\
\hline Point & 1 & 2 & 3 & 4 & 5 & 6 & 7 & 8 & 9 \\
\hline Displacement & 0.52 & 0.51 & 0.53 & 0.53 & 0.53 & 0.55 & 0.54 & 0.50 & 0.51 \\
\hline
\end{tabular}

meters of temperature cycles are $10 \%$ and in results of displacements are $14 \%$. Exactly the same results cannot be reached, because many factors (boundary condition, input data and definition of heat source) influence them.

Welding simulation has become a strong tool in technological praxis. It helps efficiently to solve complex problems in welding in a relatively short time.

\section{Acknowledgement}

This work has been supported by the Scientific Grant Agency of Ministry of Education of the Slovak Republic, grant VEGA No V-11-015-00 and KEGA No. K-11-008-00.

\section{References}

[1] FENG, Z.: Processes and Mechanisms of Welding Residual Stress and Distortion. CRC Press, USA, 2005.ISBN 978-0-8493-3467-2

[2] TOTTEN, G., HOWES, M., INOUE, T.: Handbook of Residual Stress and Deformation of Steel. AMS International, Materials Park, 2002, ISBN 0-87170-729-2

[3] http://mercury.kau.ac.kr/welding/Welding\%20Technology\%20II\%20-20Welding\%20Metallurgy/Chapter\%203\%20\%20Residual\%20Stresses.pdf

[4] MORAVEC, J.: Influence of Welding Parameters on Weld Pool's Geometry in Shielding Gas Welding. POLLYPRESS s.r.o., Liberec, 2011. ISBN 978-80-7372-805-2 